\title{
Facing reality: The cost of Alzheimer dementia-Who will pay?
}

Janet Jankowiak, MD; and David Knopman, MD

The Baby Boomers are "coming of age." They are living longer, on average, than any generation before. With this increased life span comes some real challenges. One is the expected increase in Alzheimer disease (AD) and other dementias (see About dementia predictions). As people live longer, the chances of developing AD increase markedly. At age 60 , less than $0.1 \%$ of people have dementia. By age 85, 30 to $40 \%$ have the disease. Scientists are racing against the clock to find a cure or at least a way to slow the process. In the meantime, the costs for the person with $A D$, the family, and society are mounting.

The cost of AD cannot be measured in terms of the emotional impact on the victim and his or her family. The fear of losing one's ability to think clearly is frightening. Many just hope "it won't happen to me" and click to a "more pleasant" topic. However, this is a reality that our society must face if we are to avoid putting the United States into bankruptcy.

What exactly are the costs in dollars of having dementia? In the current issue of Neurology, Zhu and others discuss this important topic (Zhu CW, Scarmeas N, Torgan R, et al. Longitudinal study of the effects of patient characteristics on direct costs in Alzheimer disease. Neurology 2006;67:998-1005). The study looked at people with probable AD in the early stages. These people were seen in three different Alzheimer clinics: in New York, Baltimore, and Boston. About 200 people were followed for 2 to 7 years.

\section{How was the study done?}

At the start of the study, the 200 people each had a full battery of tests. These included tests to make the diagnosis of probable AD. Other tests looked at each person's ability to perform activities of daily living (dressing, bathing, toileting).
Caregivers gave their input about behaviors and financial costs of caring for their loved one. Behavioral problems such as wandering away from home, yelling, or increased confusion at night were recorded. Hallucinations (seeing things or hearing voices that were not there) or delusions (believing something that was not true, like your son was robbing you) were checked if present. Depression was noted if the person's mood was sad or he or she had difficulty sleeping or a change in appetite. Because signs of Parkinson disease (PD) may be seen with certain dementias, signs of PD were also noted. These included a trembling or shaking when at rest, stiffness of an arm or leg, soft speech, and slowed/stooped walking, with a shuffle. Other illnesses such as heart attack, high blood pressure, kidney, lung, or liver disease, heart failure, diabetes, or cancer were recorded.

Progression of AD was measured every 6 months by repeating the first battery of tests. Information about costs was collected every year. It was also noted where the person was living: at home, in a retirement home, assisted living facility, or nursing home.

Direct costs of care for each person with AD were broken down into medical and non-medical care. Medical care included hospitalization, outpatient care, assistive devices (cane, wheelchair, bath stool) and medications. Non-medical care included home health aides, respite care, and adult day care.

\section{What were the results?}

At the beginning of the study, 95\% were mildly demented. By the end of the study, $8 \%$ had died. Of the rest, $71 \%$ stayed mildly demented, $19 \%$ were moderately demented, and $10 \%$ were severely demented. Initially, 86\% lived at home, $8 \%$ lived in a nursing home, and $6 \%$ in a retirement home or assisted living facility. Of interest, half the people had no other illness than mild dementia at the start of the study. About a third had one other illness, most often high blood pressure.

Everyone used some type of medical care each year, especially medications. The average number of medications increased from six at the beginning of the study to eight by the fourth year (a 25\% increase). Medication cost rose from $\$ 2,870$ to $\$ 4,300$ (a $50 \%$ increase). Total medical care cost increased by almost $50 \%$, from $\$ 7,000$ to $\$ 10,600$. On the other hand, non-medical care cost increased almost seven times, from $\$ 1,350$ to $\$ 9,350$.

Total direct cost of caring for a person with $\mathrm{AD}$ was $\$ 9,250$ at the start of the study. By the fourth year, the cost had more than doubled, to $\$ 20,000$ per year. It was noted that small declines in function led to large increases in medical care costs. In addition, developing one new illness increased the costs by $14 \%$. Of interest, total direct cost was $21 \%$ lower for patients living at home.

\section{Where do we go from here?}

This study clearly shows the dramatic increase in direct cost of caring for patients with $\mathrm{AD}$ over a relatively short time. The fact that costs are $20 \%$ lower by staying at home suggests that steps to delay or prevent moving out of home could reduce some costs. However, this potential savings needs to be balanced with the increase in cost to caregivers giving unpaid care (indirect costs). A true team effort among health care providers, family, and policy makers is needed to drive action to provide the best care for patients with $A D$ without sending the country into bankruptcy. Continued research into ways to prevent or slow the disease is equally critical. 


\section{What is the future for the Baby Boomers?}

There is a lot of talk about the effect of the baby boom generation joining the ranks of the elderly. The first of the post-war generation turned 60 this year. Over the next 50 years their impact will be felt in all aspects of care of the elderly. The costs of Social Security and Medicare are frequent topics in the lay press.

Despite being somewhat overweight and almost certainly overindulgent in their 20s and 30s, the baby boom generation will most likely be the healthiest in American history by the time they reach their senior years. The number of years they live past the retirement age of 65 is likely to be even longer than it is now. Today, an American woman who is 65 can expect to live another 19.8 years (almost 85 years old). A 65-year-old man can expect to live another 16.8 years (based on 2003 data). More and more people are living past age 75 or 85 years. People living to 100 are no longer unusual. Because the old are living longer and the Baby Boomers are entering the elderly group and there are fewer children as family size shrinks, the population in the United States is shifting toward the older end. That means that while in the year 2000, $12 \%$ of the population was over age 65 , by 2050 , it is projected that $20 \%$ of the population will be over age 65 .

\section{What is Alzheimer disease?}

Good general health does not necessarily protect against Alzheimer disease $(A D)$ and other later life dementias. AD is the most common disease that causes dementia. Early signs are problems remembering recent things (like what you had for lunch or who came to visit today) or difficulty finding the word you want. The ability to make decisions, be flexible, and solve a problem becomes more difficult. Family and friends may notice a change in personality or, more often, a worsening of the less favorable parts of a personality (becoming more shorttempered or more blunt in criticizing others). As the disease progresses, people may get lost on familiar routes, and have more difficulty following a conversation. Eventually, they even have difficulty caring for themselves (dressing, bathing, and finally even eating).

\section{Are there other types of dementia?}

Besides AD, there are several other types of dementia. The two most common ones after AD are dementia due to stroke (called vascular dementia) and a dementia often seen with PD (called Lewy body dementia; see Patient Page: Knopman D, Jankowiak J. Not all dementia is Alzheimer: dementia with Lewy bodies. Neurology 2005;65:E26-E27).

AD, vascular dementia, and Lewy body dementia all become increasingly common in late life. Before age 65, AD is uncommon. Among all people over age 65 years, it is estimated that about $5 \%$ have AD. However, when the number of people over age 65 is broken down into 5 -year intervals, the number of people with AD doubles in each of these 5 -year blocks. For example, among people between the ages of 65 and 69 years old, only about 1 in 100 people have AD. Among individuals 90 years and older, 30 to $40 \%$ have AD. There does not appear to be any decline in the number of new cases of $\mathrm{AD}$ even in the 10 th or 11 th decades of life.

\section{What does this mean?}

The combination of a growing number of older people and the fact that AD becomes more common with advancing age means that $\mathrm{AD}$ and other dementing illnesses are going to be dramatically more common over the next 50 years. In 2000, there were around 2.5 million patients with $\mathrm{AD}$ in the United States (note that there is a wide range of estimates ranging from slightly below 2 million to over 4 million). By 2050, that number will increase fourfold (Brookmeyer R, Gray S, Kawas C. Projections of Alzheimer's disease in the United States and the public health impact of delaying disease onset. Am J Public Health 1998;88:1337-1342).

Although there are many (demographic) time-bombs to worry about, the future burden of dementia due to AD has to be high on the list of the most threatening. With a smaller workforce of young people, who is going to take care of the millions of cognitively impaired elders? Nursing homes will become the prime industry in many regions, but who will pay for the enormous costs?

\section{What can be done?}

These are not questions that can be ignored. Nor can decisions be made purely on an economic basis by politicians or self interests who see a chance to make money. Although the issues become very emotional when one has a family member with dementia, a long-term, carefully crafted plan is needed. This will require a team effort. At the table there must be the health care providers who know the course of dementia and how to manage it, practical people who understand the economics of the situation, policy makers who can enact a plan, and leaders who can bring consensus. At the same time, those who care about these issues must continue to push for further funding of research to slow, halt, and eventually cure AD and its devastating cousins.

\section{For more information}

Alzheimer's Association: www.alz.org

American Geriatrics Society: www.americangeriatrics.org 


\section{Neurology}

\section{Facing reality: The cost of Alzheimer dementia--Who will pay? Janet Jankowiak and David Knopman Neurology 2006;67;E11-E12 \\ DOI 10.1212/01.wnl.0000240882.63507.d7}

This information is current as of September 25, 2006

\author{
Updated Information \& \\ Services \\ Supplementary Material \\ Citations \\ Permissions \& Licensing \\ Reprints
}

including high resolution figures, can be found at: http://n.neurology.org/content/67/6/E11.full

Supplementary material can be found at: http://n.neurology.org/content/suppl/2007/11/08/67.6.E11.DC1

This article has been cited by 1 HighWire-hosted articles: http://n.neurology.org/content/67/6/E11.full\#\#otherarticles

Information about reproducing this article in parts (figures,tables) or in its entirety can be found online at:

http://www.neurology.org/about/about_the_journal\#permissions

Information about ordering reprints can be found online:

http://n.neurology.org/subscribers/advertise

Neurology ${ }^{\circledR}$ is the official journal of the American Academy of Neurology. Published continuously since 1951, it is now a weekly with 48 issues per year. Copyright . All rights reserved. Print ISSN: 0028-3878. Online ISSN: 1526-632X.

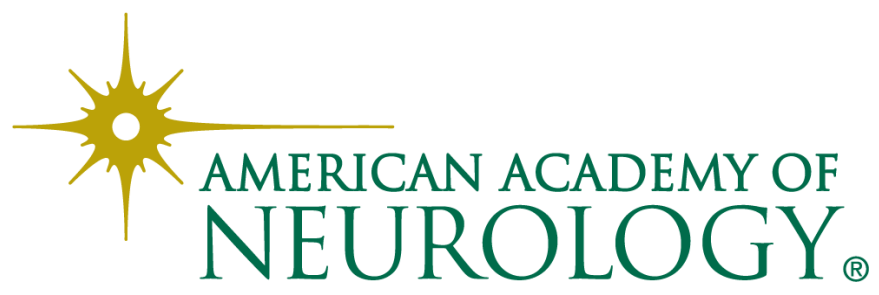

